\title{
Introduction: Power and space in the drone age
}

\author{
Francisco Klauser and Silvana Pedrozo \\ Institut de Géographie, Université de Neuchâtel, Esapce Louis Agassiz 1, \\ 2000 Neuchâtel, Switzerland \\ Correspondence to: Francisco Klauser (francisco.klauser@unine.ch) \\ and Silvana Pedrozo (silvana.pedrozo@unine.ch)
}

Published: 28 November 2017

In recent years, a growing social-scientific literature has emerged that focuses on drones in military conflict (Gregory, 2011; Wall and Monahan, 2011; Williams, 2011). In contrast, civil applications of drones have remained widely unnoticed in academic research, despite some notable exceptions (Clarke, 2014; Thompson and Bracken-Roche, 2015; Jablonowski, 2015). Addressing this research lacuna, this theme issue brings together nine full papers and two intervention essays, which together provide deepened insight into differing applications, interests, and actors in the field of civil drone utilization, so as to generate a wider picture of the opportunities and risks associated with the societal diffusion of drone technology.

The collection also affords insight into the driving forces that are behind current drone developments, shows how drones work in different institutional contexts, and highlights how drones enable action upon the envisioned reality. In so doing, it also aspires to more fully grasp and theorize the role of the aerial dimension in the projection of power across and within space. Thus, importantly, the collection starts from the basic assumption that a distinct "spatial curiosity" and "power sensitivity" are required in order to understand the logics, functioning, and implications of drones; this in turn justifies the geographical positioning and orientation of the theme issue. The papers brought together here are structured into three main parts.

\section{Politics of the ground}

The first part of the theme issue explores the ways in which drones enable action on the ground. The first paper, written by Francisco Klauser and Silvana Pedrozo, serves as an extended introduction to this problematic and as a broader framework for the theme issue more generally. It works out an understanding of drones as aerial techniques of power that are intrinsically bound up with space, and as such opens up a reflection on the possibility of a specifically politicogeographical approach to the drone problematic.

The two papers that follow, written by Ian Shaw and Silvana Pedrozo, explore the spatial logics and power issues involved in the deployment of drones for policing purposes in the context of cities and border regions respectively. In complementary ways, the papers also shed light on the collaborations between military and police users of the technology. Ian Shaw, on the one hand, offers a critical assessment of the modalities and driving forces behind the police use of drones for monitoring populations in European and North American cities. He advances a reflection on the rise of the "dronepolis", a city shaped by a wide and diverse assemblage of surveillance technologies. Silvana Pedrozo, on the other hand, analyses the deployment of military drones by Swiss border guards, an entity of the Swiss federal police. Her paper shows how the mobile and flexible nature of drones has changed the monitoring of the Franco-Swiss border, affected identification checks on the ground, and shaped the sociospatial relations that the border guards maintain with the border area.

Moving away from the issue of state power, the two other articles in this section centre around the usage of drones for purposes of popular resistance, protest, and activism. Drawing upon action research conducted along the Kapuas River in West Kalimantan, Indonesia, the paper written by Irendra Radjawali and Oliver Pye explores how drones were used by grassroots activists to generate photographs and GPSreferenced maps for political interventions against land grabs by palm oil and mining companies. This highlights the inclusive and emancipatory potential of the technology, and its significance as a space-bound technique of counterpower. Neil Waghorn's paper further pursues this discussion, with regard to the usage of protester-operated drones in the con- 
text of political demonstrations. Referring to examples from the UK, Waghorn explores the potential of unmanned aerial vehicles to monitor, record, and relay information about police movements to protestors on the ground. On this basis, Waghorn not only discusses the ways in which the unfolding "protester panopticon" increases accountability and selfdiscipline amongst the police but also underscores the legal, practical, technological, and physical forms of police resistance to this evolution.

\section{Making of the drone}

The second part of the theme issue brings together three papers that focus on the actors, interests, and collaborations behind the contemporary geographies of drone utilization. To start, Ciara Bracken-Roche's essay critically examines the driving forces that shape the proliferation of drones, with a view to challenging the surveillance issues and asymmetries of power and visibility generated by the technology. Building on the Canadian case, the essay argues that the technology's success is due not only to its usefulness but also to the expectations, socio-political dynamics, and economic interests it evokes. Anna Jackman's essay further develops this argument, studying how drones are framed, advertised, and sold in trade-show environments. As Jackman shows, trade exhibitions are key sites for stakeholders to meet and thus are hubs for shaping how drones will be imagined, understood, regulated, and used in future years. The last paper of this section, written by Francisco Klauser and Silvana Pedrozo, completes this reflection from the viewpoint of the general population. It draws upon a public opinion poll conducted in Switzerland, so as to highlight the popular fears and hopes associated with the technology. This opens up a wider reflection on the societal production of the airspace in the drone age.

\section{Theorizing the drone}

The third part of this theme issue brings together three conceptually oriented papers. Firstly, Peter Adey's contribution situates drones within the wider Western history of the aerial figure of the levitator. This invites an engagement with the drone problematic that moves beyond the usual techno-legal and scientific levels, to also focus on theological, mythological, magical, and aesthetic registers and opens up alternative understandings of the air as an ambiguous, mystical, and highly gendered social reality.

Secondly, Jeremy Crampton conceptualizes drones as "assemblages of the vertical". Referring to the example of commercial drones most notably, the paper pushes for an approach to the drone problematic that focuses on the sociotechnical mediations through which drones are made to act, and on the affects and effects produced by the technology, rather than on the object itself.
Finally, Ole Jensen's paper approaches the phenomenon of drones through the lens of the so-called "mobilities turn" and its recent re-development towards design. This foregrounds yet another set of key issues and dimensions of the problematic, related to the aerial vehicles' place and role within the contemporary smart city as a context shaped by networked, automated, and thus inherently surveillant, digital technologies.

Together, the contributions brought together in this theme issue advance a number of thought-provoking conceptual and analytical claims, which offer an agenda-setting panorama for future academic engagements with the drone problematic, and which underscore again and again the fundamentally spatial functioning and logics of drone technology.

\section{References}

Clarke, R.: The regulation of civilian drones' impacts on behavioural privacy, Comput. Law Secur. Rev., 30, 286-305, 2014.

Gregory, D.: From a view to a kill drones and late modern war, Theor. Cult. Soc., 28, 188-215, 2011.

Jablonowski, M.: Drone It Yourself! On the Decentring of 'Drone Stories, Culture Machine, 16, 1-15, 2015.

Thompson, S. and Bracken-Roche, C.: Understanding public opinion of UAVs in Canada: A 2014 analysis of survey data and its policy implications, Journal of Unmanned Vehicle Systems, 3, 156-175, 2015.

Wall, T. and Monahan, T.: Surveillance and violence from afar: The politics of drones and liminal security-scapes, Theor. Criminol., 15, 239-254, 2011.

Williams, A. J.: Reconceptualising spaces of the air: Performing the multiple spatialities of UK military airspaces, T. I. Brit. Geogr., 36, 253-267, 2011. 